\title{
Implementation flow control to improve quality of service on computer networks
}

\author{
Ahmad Khafidin, Tatyantoro Andrasto, Suryono \\ Department of Electrical Engineering, State University of Semarang, Indonesia
}

\begin{tabular}{l}
\hline Article Info \\
\hline Article history: \\
Received Feb 12, 2019 \\
Revised Jun 1, 2019 \\
Accepted Jul 28, 2019
\end{tabular}

\section{Keywords:}

Delay

Flow control

Jitter

Packet loss

Quality of service

Throughput

\begin{abstract}
Quality of Service (QoS) is the collective effect of service performances, which determine the degree of satisfaction of a user of the service. In addition, QoS defined as the ability of a network to provide good service. QoS aims to provide different quality of services for various needs in the IP network. QoS parameters that can be used to analyze the data communication services are jitter, packet loss, throughput, and delay. The quality of QoS parameters in the network is affected by congestion. Congestion occurs because there is an excessive queue in the network. Congestion can be prevented by implementing flow control on network. Flow control is a method to control the data packet flow in a network. By controlling of the data packet flow, it can improve of QoS. This study intends to find out value of QoS on the internet network at Faculty Engineering, State University of Semarang by measuring network performance using QoS parameters. Then, in this research will be implemented the token bucket method as a flow control mechanism at the network to improve the QoS. After research and data analysis, internet network at Faculty Engineering State University of Semarang has QoS value was 3,5 with 87,5\% of percentage and classified in satisfying of category. When measuring the network performance, there are decreases of performance at access point that having data rates $150 \mathrm{Mbps}$ with many users connected. It has $9,0 \mathrm{~ms}$ of delay value, $0.046 \mathrm{~ms}$ of jitter, $16,6 \%$ of packet loss and, 1293407 bps of throughput. After token bucket was applied as flow control mechanism that be simulated on Graphical Network Simulator 3, the internet network has QoS values 3,75 with 93,75\% of percentage and classified as "satisfying" category. Furthermore, the percentage of the throughput value obtained on network by implementing flow control is $62 \%$, while on the existing network is $41 \%$.
\end{abstract}

Copyright $@ 2019$ Institute of Advanced Engineering and Science. All rights reserved.

\section{Corresponding Author:}

Ahmad Khafidin,

Department of Electrical Engineering,

State University of Semarang, Indonesian.

Email: khafidin.apit@students.unnes.ac.id

\section{INTRODUCTION}

Internet network is a group of computers that are connected to each other in large scale so that each computer can communicate with others and share resources. Reference [1] states that, a device can be said to be a network if they can exchange information. Reference [2] states that, in Indonesia the internet is very needed because it facilitates the communication process without being constrained by distance and time. The development of the internet network is very influential in every aspect of human life, one of which is education. The advantages provided by the internet network in education are very supportive for the learning process [3]. The advantage of the internet is quite large for learning activities. Students and lecturers often use the internet to find literature needed for academic activities, one of them is learning activities. In addition, internet networks are also used by educational institutions to implement administrative activities. The internet 
network is very important in education. Therefore, in the educational institution which wants to improve the quality of education implementation must have good internet network quality. Quality of Service (QoS) is the collective effect of service performances, which determine the degree of satisfaction of a user of the service [4]. In addition, QoS defined as the ability of a network to provide good service [5]. In other study, Quality of Service (QoS) defined a method of measurement of how well a network is and is an attempt to define the characteristics and quality of a service. QoS aims to provide different quality services for various needs in the IP network. In [6], One important factor that is affected on the QoS service is the transport layer. Currently, the most common transport protocols used by internet application are TCP (Transmission Control Protocol) and UDP (User Datagram Protocol). Reference [7] states that, there are several factors that affect the decrease of performance on the network, it can be observed from the changes in the quality of QoS parameters measured. Reference [8,9] states that QoS parameters used for analysis of data communication services or network transmission are jitter, packet loss, throughput and delay.

The quality of QoS parameters in the network is affected by congestion. Reference [7, 10] states that, packet loss and jitter are affected by variations in traffic load and the number of collisions between packets or congestion on the network. And delay can be influenced by distance, physical media, congestion or long processing time. Congestion occurs because the output capacity is smaller than the inflow on the router, that resulting in excessive queues in the network $[5,7]$.

Congestion can be prevented by implementing flow control on network [11]. Flow control is the management data flow in the network so that data can be handled at an efficient speed [12]. Flow control is used to prevent queues from exceeding capacity, regulating the allocation of buffers and links on each router, and determining when buffers and links will be used. So, by controlling the flow of data packets on computer networks can improving QoS [13]. One of the flow control mechanisms that can be applied to improve QoS is traffic shaping with the token bucket method. Then [14] token bucket is a mechanism to control the rate of network traffic given to the network. Token bucket uses the Token Bucket Filter (TBF) as an estimator to determine whether a class is in an under limit, at limit or over limit. TBF works with the base of the token bucket, each packet to be sent must have a token on the bucket. If the token is not available in the bucket, then the packet to be sent must wait until enough tokens are available to send the packet. Token bucket is able to maximize unused bandwidth, so that service quality becomes more increased. A number of studies have been conducted to find out and improve QoS on a network. Research [15] aims to analyze QoS on internet networks by measuring network performance using QoS parameters, namely delay, jitter, packet loss and throughput. Research [16] aims to improve QoS by proposing a scheduling algorithm based on increasing minimal resources to minimize resources and maintain QoS. Research [17] aims to use HTB as bandwidth management on a network as one method for implementing QoS. In this research, the researcher compared the network quality before and after using HTB. The results of the research show that after using HTB, internet access can be controlled and each client gets the required bandwidth.

This study aims to find out the Quality of Service internet network at the Faculty Engineering State University of Semarang by analyzing network performance using parameters of delay, jitter, packet loss, and throughput. The researcher implementing token bucket as a mechanism to controlling the flow of data packets to improve Quality of Service on the internet network.

\section{RESEARCH METHOD}

\subsection{Model and Development Procedure}

The development model system used in this research is Network Development Life Cycle (NDLC). NDLC is a method to design and develop the infrastructure of a network [18]. In the NDLC method, there are six stages. They are analysis, design, simulation prototyping, implementation, monitoring and management [19]. The application stages of NDLC method in this research is according to the research needs because of the limited time and research funds. So that in this research only uses three stages of NDLC. They are analysis, design and simulation prototyping.

\subsubsection{Analysis}

In this stage, an analysis of network at Faculty Engineering of UNNES. Analysis of network done by:

a) Field study to find out the current condition of Faculty Engineering networks. Field studies were carried out by observation and interviews with network managers at the Faculty and Department.

b) Measuring network performance by accessing the internet (download, upload, and streaming). Data flow that occurs when accessing the internet is captured with Wireshark software.

When retrieving data on access point used by many users, there is a decrease in the speed of internet access. While in other access points used by few users, there is no significant decrease in the internet access 
speed. In connection with the statement before, it could be concluded that an indication of the problem is based on the quality of access point used.

Table 1 is an analysis table of the access point capabilities possessed by Faculty of Engineering on the data rate given to users of $10 \mathrm{Mbps}$. From the Table 1, it could be seen the smallest data rates owned on the Asus RT N10U, TP-Link TL WA701ND, and UBNT NSM5 access point of 150 Mbps. When compared with a data rate owned by users of $10 \mathrm{Mbps}$, so the maximum number of users that can be accommodated on access point to can be work properly is 15 users. However at the same time, the access point can be accessed more than 15 users.

Table 1. Analysis of Access Point Ability to Data Rate User 10 Mbps

\begin{tabular}{ccccc}
\hline Brand & Model & Data Rates & Rate of User & $\begin{array}{c}\text { Max Amount } \\
\text { of Users }\end{array}$ \\
\hline Asus & RT N10U & Up to 150 Mbps & & 15 \\
D-Link & DIR 300 & Up to 54 Mbps & & 5 \\
Linksys & LAPAC 1200 & Up to 1200 Mbps & & 120 \\
Linksys & LAPN 600 & Up to 600 Mbps & 10 Mbps & 60 \\
TP-Link & TL WA701ND & Up to 150 Mbps & & 15 \\
TP-Link & TL WR840N & Up to 300 Mbps & & 30 \\
UBNT & NSM5 & Up to 150 Mbps & & 15 \\
\hline
\end{tabular}

\subsection{Design}

At this stage, the network design is done to resolve the problems that occur. In this design the researcher manages traffic on the network by controlling the flow of data packets for each connection in the network using token bucket method. By controlling the flow of data packets in the network can improve Quality of Service. Mechanism of flow control are applied in this research is traffic shaping using the token bucket method.

Token bucket was chosen because it can maximize unused bandwidth, so if there is a class that lacks of bandwidth, so will be given from the parent class. The implementation of token bucket on mikrotik in this research is applied to the queue tree with the following steps:

a) Mark the packet for each client connection in the Mangle configuration.

b) Make Queue with type Per Connection Queue (PCQ) to give Maximum Information Rate for each packet type.

c) Entering Parent, Packet Mark, and Queue Type on each packet through the Queue Tree configuration.

Table 2 is packets will be marked on mangle and the maximum data rate that will be given to each packet.

Table 2. Packet Mangle and Bandwidth Allocation

\begin{tabular}{cccccc}
\hline No & Packet & Connection Bytes & Type & Queue Type & Max Rate \\
\hline 1 & Heavy Traffic & $>625000$ & Download/ Upload & \multirow{2}{*}{ PCQ } & 5 Mbps \\
2 & Light Traffic & $<625000$ & Download/ Upload & & 4 Mbps \\
\hline
\end{tabular}

From the Table 2, it could be seen that the marked package for each connection on the client is categorized as a heavy traffic packet, and a light traffic packet. It is said to be a heavy traffic packet when there is a connection request of more than 625000 bytes continuously. When there is a connection request less than 625000 bytes, it is said to be a light traffic packet. The Data rate will be allocated for heavy traffic packets for both download or upload is a maximum of $5 \mathrm{Mbps}$. While the data rate will be allocated for light traffic packets for both download or upload is a maximum of $4 \mathrm{Mbps}$.

\subsubsection{Simulation Prototyping}

At this stage, a prototype simulation is made according to the design that has been designed. Prototype simulations are made by using Graphical Network Simulator 3 (GNS3) software that integrated with VirtualBox. In the virtualbox, the operating system is installed to simulate internet networks including mikrotik 5.20, debian 7.2 and windows 7. Mikrotik 5.20 is used as routers in the network, debian 7.2 is used as a server, and windows 7 is used as clients. The topology in network simulation is made based on real network mapping at the Faculty Engineering State University of Semarang, which consists of eight routers, one server and two clients as shown in Figure 1. Seven of the eight routers, which are used to build local networks in each building, are configured with flow control by implementing token bucket to control the 
flow of data packets in the network. The server is given a freeradius configuration which is used as login authentication on the network. In addition, the researcher also used the Winbox application to make it easier when configure the mirotik router and the wireshark to capture data traffic during network simulation testing. Wireshark is used to capture network traffic between routers [20].

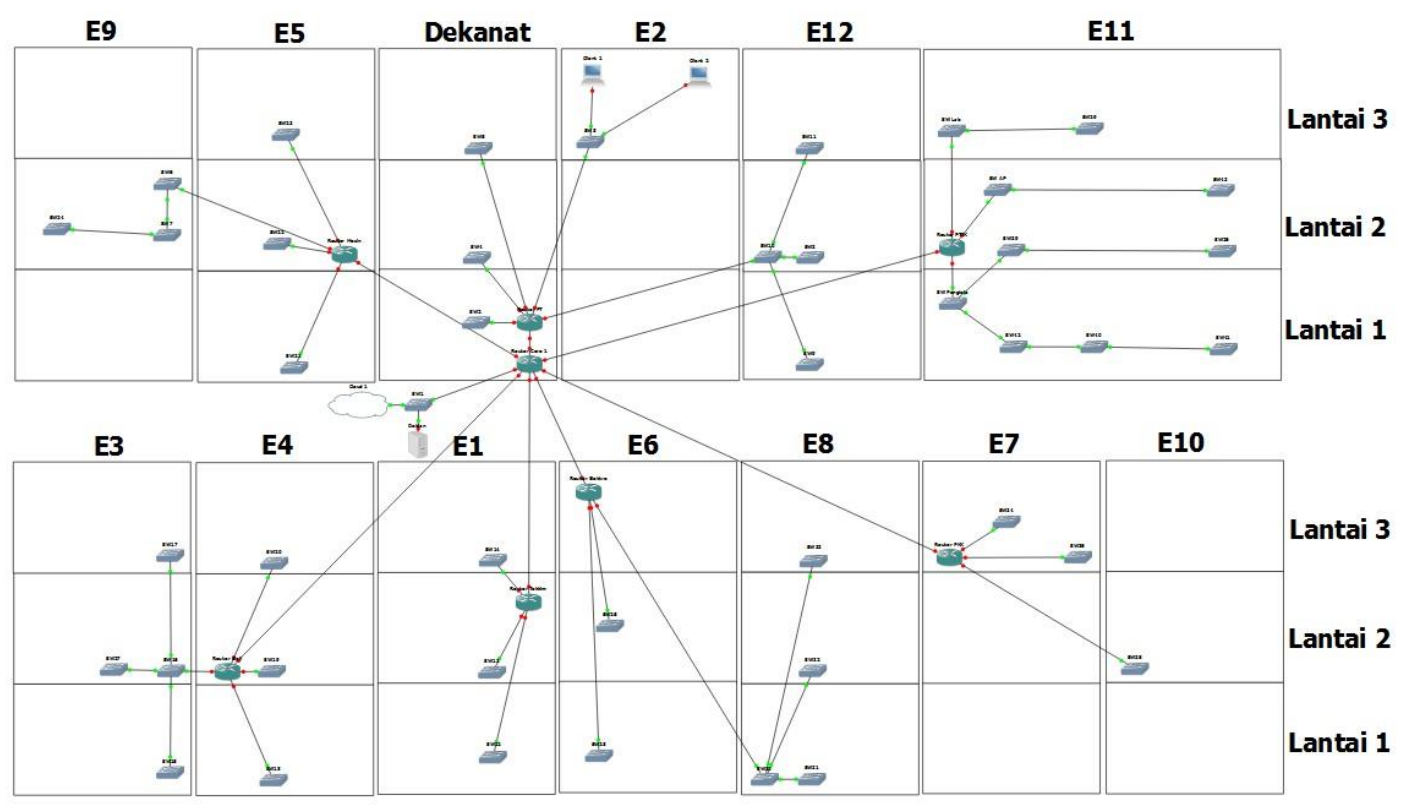

Figure 1. Network Simulation on software Graphical Network Simulator 3

\subsection{Measurement of Network Simulation}

Tests on products need to be done in order to find out how well the simulations are produced to improve QoS of internet network at Faculty Engineering of UNNES. Testing is done from the client side, client will download the K-Lite Mega Codec Pack 14.6.5 which has 54.59 MB file size on FileHippo, video streaming with 360p quality and 5 minutes 11 seconds duration on YouTube, and uploading the K-Lite Mega Codec Pack 14.6.5 which has 54.59 MB file size on Google Drive. Then the data flow on the traffic between the client and router was captured using Wireshark software to obtain data traffic in the network. Retrieval of data in network simulation was done by three experiments. The three experiments has different concepts, they are:

a) The first experiment, retrieval of data is done at an active router with only 1 active client.

b) The second experiment, retrieval of data is done at an active router with 2 active clients.

c) The third experiment, retrieval of data is done at 1 of 2 active routers with 1 active client at each router.

In analyzing the data, the researcher used data analysis four variables from QoS parameters. They are delay, jitter, packet loss, and throughput. Technique for analyzing the data of IP network quality at Faculty Engineering of UNNES has the following steps:

a) Calculates the value of each Quality of Service parameters

$$
\begin{aligned}
& \text { [21] Delay rata }- \text { rata }=\frac{\text { Number of delay }}{\text { Number of received packets }} \\
& \text { [22] Jitter }=\frac{\text { Number of } \text { elay variation }}{\text { Number of received packets-1 }} \\
& \text { [23] Percentage Packet Loss }=\frac{\text { (Number of sent packets-Number of received packets) }}{\text { Number of sent packets }} \text { X } 100 \\
& \text { [23] Throughput }=\frac{\text { Number of received packets } \times 8}{\text { Simulation time }}
\end{aligned}
$$

b) Changing the value of each parameter into indexes and categories that can see in Figure 3 until Figure 6. 


\begin{tabular}{|c|c|c|}
\hline Delay Category & Delay (ms) & Index \\
\hline Perect & $<150 \mathrm{~ms}$ & 4 \\
\hline Good & $150 \mathrm{~ms} \mathrm{~s} / \mathrm{d} 300 \mathrm{~ms}$ & 3 \\
\hline Medium & $300 \mathrm{~ms} \mathrm{~s} / \mathrm{d} 450 \mathrm{~ms}$ & 2 \\
\hline Poor & $>450 \mathrm{~ms}$ & 1 \\
\hline
\end{tabular}

(Source: TIPHON on [24])

Table 5. Index and Category of Packet Loss Value

\begin{tabular}{ccc}
\hline Packet Loss Category & Packet Loss (\%) & Index \\
\hline Perect & 0 & 4 \\
Good & 3 & 3 \\
Medium & 15 & 2 \\
Poor & 25 & 1 \\
\hline
\end{tabular}

(Source: [25])
Table 4. Index and Category of Jitter Value

\begin{tabular}{ccc}
\hline Jitter Category & Jitter $(\mathrm{ms})$ & Index \\
\hline Perect & $0 \mathrm{~ms}$ & 4 \\
Good & $0 \mathrm{~ms} \mathrm{~s} / \mathrm{d} \mathrm{75} \mathrm{ms}$ & 3 \\
Medium & $75 \mathrm{~ms} \mathrm{~s} / \mathrm{d} 125 \mathrm{~ms}$ & 2 \\
Poor & $125 \mathrm{~ms} \mathrm{~s} / \mathrm{d} 225 \mathrm{~ms}$ & 1 \\
\hline
\end{tabular}

(Source: [25])

Table 6. Index and Category of Throughput Value

\begin{tabular}{ccc}
\hline Throughput Category & Throughput (bps) & Index \\
\hline Perect & 100 & 4 \\
Good & 75 & 3 \\
Medium & 50 & 2 \\
Poor & $<25$ & 1 \\
\hline
\end{tabular}

(Source: TIPHON on [24])

c) Calculates value of Quality of Service based on index of each parameter using the formula

$$
Q o S=\frac{\sum I P}{N}
$$

Information:

$\begin{array}{ll}\text { QoS } & =\text { QoS Value } \\ \sum \text { IP } & =\text { Amount of Parameter Index } \\ \mathrm{N} & =\text { Number of Parameters (4) }\end{array}$

d) Changing the value of QoS becomes a qualitative value (Figure 7)

Table 7. Quality of Service Value

\begin{tabular}{ccc}
\hline Value & Percentage $(\%)$ & Index \\
\hline $3,8-4$ & $95-100$ & Very Satisfying \\
$3-3,79$ & $75-94,75$ & Satisfying \\
$2-2,99$ & $50-74,75$ & Less Satisfying \\
$1-1,99$ & $25-49,75$ & Poor \\
\hline \multicolumn{3}{c}{ (Source: TIPHON on [24]) }
\end{tabular}

\section{RESULTS AND ANALYSIS}

This section describe the results of the QoS analysis on existing networks of the faculty Engineering, State University of Semarang without any flow control in the network and QoS analysis by implementing flow control using token bucket method are obtained from network simulation. Both analyzes are discussed separately.

\subsection{Values of QoS Parameters on the Existing Network without any Flow Control on the Network}

The calculation value of each QoS parameters obtained in performance measuring on existing network by downloading, streaming and uploading taken on all points of internet access is shown in Table 8 .

Table 8 is a recapitulation of QoS parameters value on Faculty Engineering's internet network obtained by measuring network performance by using a user who has a data rate of $10 \mathrm{Mbps}$. Based on the table 8, it could be seen that the Faculty Engineering's internet network has a value of average delay is $7.5 \mathrm{~ms}$ with index value is 4 and classified in very good category. Value of jitter is $0.01 \mathrm{~ms}$ with index value 3 and classified in good category, value of packet loss is $5.0 \%$ with index value is 3 and classified in good category, and value of throughput is 4070192 bps with index value is 4 and classified in very good category. So that it could be concluded that the internet network at Faculty Engineering, State University of Semarang has QoS value was 3.5 with $87.5 \%$ percentage and classified in satisfying category based on THIPON standards. However, when measuring network performance there is a decrease of the network performance at the access points, which has data rates $150 \mathrm{Mbps}$ when used by more than 15 users. Table 9 is compares the value of QoS parameters on access points that have data rates of $150 \mathrm{Mbps}$ when there is a decrease and no decrease in performance. 
Table 8. Data Recapitulation of QoS Parameters on Exsisting Network

\begin{tabular}{|c|c|c|c|c|c|}
\hline \multirow{2}{*}{ No } & \multirow{2}{*}{ Location } & \multicolumn{4}{|c|}{ Quality of Service Parameters } \\
\hline & & Delay (ms) & Jitter (ms) & Packet Loss $(\%)$ & Throughput (bps) \\
\hline 1 & Dekanat Building & 3.3 & 0.0023 & 4.2 & 4374603 \\
\hline 2 & E1 Building & 6.9 & 0.0011 & 6.2 & 3819003 \\
\hline 3 & E2 Building & 4.5 & 0.0026 & 5.5 & 3335698 \\
\hline 4 & E3 Building & 12.4 & 0.056 & 6.9 & 3207491 \\
\hline 5 & E4 Building & 8.6 & 0.00044 & 5.4 & 3804957 \\
\hline 6 & E5 Building & 5.9 & 0.0009 & 2.7 & 5358312 \\
\hline 7 & E6 Building & 3.1 & 0.0016 & 3.0 & 4874002 \\
\hline 8 & E7 Building & 6.6 & 0.0026 & 3.8 & 3253751 \\
\hline 9 & E8 Building & 4.9 & 0.027 & 3.4 & 4720042 \\
\hline 10 & E9 Building & 6.7 & 0.011 & 8.0 & 4397463 \\
\hline 11 & E10 Building & 20.7 & 0.011 & 8.0 & 3729558 \\
\hline 12 & E11 Building & 6.8 & 0.0011 & 4.1 & 3280472 \\
\hline \multirow[t]{4}{*}{13} & E12 Building & 6.5 & 0.001 & 3.4 & 4757147 \\
\hline & Average & 7.7 & 0.01 & 5.0 & 4070192 \\
\hline & Index & 4 & 3 & 3 & 4 \\
\hline & Category & Perfect & Good & Good & Perfect \\
\hline
\end{tabular}

Table 9. Comparison of QoS Parameters value

\begin{tabular}{ccc}
\hline \multicolumn{3}{c}{ Access Point with Data Rates Up to 150 Mbps } \\
No & Decrease of Performance & Yes \\
\hline 5.7 & Delay (ms) & 9.0 \\
0.000066 & Jitter (ms) & 0.046 \\
2.9 & Packet Loss (\%) & 16.6 \\
6663938 & Throughput (bps) & 1293407 \\
\hline
\end{tabular}

From Table 9, it is known that the value of the QoS parameter when there is a decrease in network performance has a bad value compared to when there is no decrease in network performance. When there is a decrease in network performance, the user gets a throughput of 1293407 bps, which is much smaller than the throughput or data rate allocated to the user of $10000000 \mathrm{bps}$ or $10 \mathrm{Mbps}$.

\subsection{Values of QoS Parameters on the Network by Implementing Flow Control using Token Bucket Method}

Based on the results of the design and simulation prototyping by implementing token bucket as a flow control mechanism, then obtained the calculation value of each QoS parameter in measuring network simulation performance by downloading, streaming and uploading is shown in Table 10.

Table 10. Data Recapitulation of QoS Parameters on Network Simulation

\begin{tabular}{|c|c|c|c|c|c|}
\hline \multirow{2}{*}{ No } & \multirow{2}{*}{ Location } & \multicolumn{4}{|c|}{ Quality of Service Parameters } \\
\hline & & Delay (ms) & Jitter (ms) & Packet Loss (\%) & Throughput (bps) \\
\hline 1 & Dekanat Building & 5.39 & 0.001 & 0.102 & 3398407 \\
\hline 2 & E1 Building & 5.75 & 0.003 & 0.101 & 3060953 \\
\hline 3 & E2 Building & 6.13 & 0.0004 & 0.091 & 3102098 \\
\hline 4 & E3 Building & 5.67 & 0.0003 & 0.109 & 2990108 \\
\hline 5 & E4 Building & 5.61 & 0.001 & 0.089 & 2944006 \\
\hline 6 & E5 Building & 5.72 & 0.0004 & 0.070 & 3510516 \\
\hline 7 & E6 Building & 5.67 & 0.0004 & 0.103 & 3286377 \\
\hline 8 & E7 Building & 5.58 & 0.0001 & 0.099 & 3112318 \\
\hline 9 & E8 Building & 6.43 & 0.0003 & 0.122 & 2943881 \\
\hline 10 & E9 Building & 5.34 & 0.0002 & 0.124 & 2984658 \\
\hline 11 & E10 Building & 3.97 & 0.0002 & 0.105 & 3092735 \\
\hline 12 & E11 Building & 7.07 & 0.001 & 0.116 & 2472019 \\
\hline \multirow[t]{4}{*}{13} & E12 Building & 5.64 & 0.0005 & 0.094 & 3179987 \\
\hline & Average & 5.69 & 0.001 & 0.102 & 3082928 \\
\hline & Index & 4 & 3 & 4 & 4 \\
\hline & Category & Perfect & Good & Perfect & Perfect \\
\hline
\end{tabular}

Table 10 is a recapitulation of QoS parameters value on network simulation by implementing flow control using token bucket method and the maximum data rate are allocated to users is $5 \mathrm{Mbps}$. Retrieval of data is done with three experiment. Of the three measurements that have been done, there are 13 samples data of QoS parameters in network simulation. From calculation of data recapitulation each QoS parameters, it is 
obtained a value of average delay is $5.69 \mathrm{~ms}$ with index value is 4 and classified in very good category. The value of jitter is $0.001 \mathrm{~ms}$ with index value is 3 and classified in good category. The value of packet loss is $0.102 \%$ with index value is 4 and classified in very good category, and value of throughput is 3082928 bps with index value is 4 and classified in very good category. So, based on the index value of each parameter it could be concluded that QoS value of network simulation is 3.75 with $93.75 \%$ of percentage and classified in satisfying category based on THIPON standards.

\subsection{Analysis}

.Network design that is expected to improve QoS by implementing flow control using token bucket method as a data packet flow control mechanism on network has a good value for measuring QoS parameters compared to network existing measurements both, when there are decrease in network performance and recapitulation measurement values. Which network design by implementing flow control in the network has an average delay value is $5.69 \mathrm{~ms}$, value of jitter is $0.001 \mathrm{~ms}$, value of packet loss is $0.102 \%$, and value of throughput is 3082928 bps. While, the results of existing network measurements when there is a decrease of performance has a value of average delay is $9.0 \mathrm{~ms}$, jitter is $0.046 \mathrm{~ms}$, packet loss is $16.6 \%$, and throughput is $1293407 \mathrm{bps}$. And the results show that the network of Faculty Engineering has an average delay value is 7.5 $\mathrm{ms}$, jitter is $0.01 \mathrm{~ms}$, packet loss $5.0 \%$, and throughput is $4070192 \mathrm{bps}$. The Table 11 compares the value of QoS parameters on real networks, decreases of performance in real networks, and network simulations.

Table 11. Comparison of QoS Parameters Value

\begin{tabular}{cccc}
\hline \multirow{2}{*}{ QoS Parameters } & \multicolumn{2}{c}{ Existing Network } \\
& $\begin{array}{c}\text { Recapitulation in } \\
\text { Existing Network }\end{array}$ & $\begin{array}{c}\text { Decrease in Network } \\
\text { Performance }\end{array}$ & $\begin{array}{c}\text { Network } \\
\text { Simuation }\end{array}$ \\
\hline Delay (ms) & 7,5 & 9,0 & 5,69 \\
Jitter (ms) & 0,01 & 0,046 & 0,001 \\
Packet Loss (\%) & 5,0 & 16,6 & 0,102 \\
Throughput (bps) & 4070192 & 1293407 & 3082928 \\
\hline
\end{tabular}

Based on the maximum throughput of data rates are allocated to users on existing network of 10 Mbps then from Table 11 can be know that in general, user get the throughput value are averages $41 \%$ on the existing network and when there is a decrease in performance on the existing network, user only get $13 \%$ of the throughput are allocated. While based on the throughput or maximum data rate are allocated to the user when implementing flow control by $5 \mathrm{Mbps}$, it can be know that the user get an average throughput of $62 \%$ of the maximum throughput are allocated.

\section{CONCLUSION}

In this paper, research on QoS has been carried out on the internet network of the Faculty Engineering, State University of Semarang and implementing flow control to controling the flow of data packets in the network using the token bucket method which is simulated by GNS3. The results of the research could be concluded that in general, the network quality of Faculty Engineering of UNNES is classified in "satisfying" category with QoS value is 3.5. It was based on THIPON standards. But, there are a decrease of performance when measuring the network performance. It could be seen on the access points that have data rates is $150 \mathrm{Mbps}$; it was used more than 15 users. While by implemented flow control on network using token bucket method are obtained the results measurement QoS value is 3.75, and it is classified in the "satisfying" category. In addition, by implemented flow control on the network, the value of QoS parameters is better than the existing network, both when there are decrease in network performance or the recapitulations value of QoS parameters on existing network. The percentage of the throughput value obtained is also greater, which is $62 \%$, while on the existing network it is $41 \%$ and when there are decrease in performance it only gets $13 \%$ from the throughput are alocated.

\section{REFERENCES}

[1] L. S. Ezema, et al., "Plan, Design and Simulation of University Network," Int. J. Adv. Comput. Res., vol. 4, pp. 834-842, 2014.

[2] A. P. Masero, et al., "Perancangan Pengelolaan Jaringan IT Pada Institut Sains \& Teknologi AKPRIND Menggunakan Teknologi VPN," Jarkom, vol. 1, pp. 20-30, 2013.

[3] A. Rahman and Haviluddin, "Implementation of Bandwidth Management Authentication," Int. J. Comput. Informatics, vol. 1, pp. 1-8, 2016. 
[4] ITU-T E.800, "Definitions of terms related to quality of service," Int. Telecommun. Union, vol. 9, 2008.

[5] M. Arijana, et al., "Quality of Service in Multimedia Computer Networks," DAAAM Int., vol. 22, pp. 227-228, 2011.

[6] A. H. Wheeb, "Performance Evaluation of UDP , DCCP , SCTP and TFRC for Different Traffic Flow in Wired Networks," Int. J. Electr. Comput. Eng., vol. 7, pp. 3552-3557, 2017.

[7] W. Sugeng, et al., "The Impact of QoS Changes towards Network Performance," Int. J. Comput. Networks Commun. Secur., vol. 3, pp. 48-53, 2015.

[8] O. Said, "Performance evaluation of WSN management system for QoS guarantee," EURASIP J. Wirel. Commun. Netw., pp. 1-18, 2015.

[9] S. Kaur and G. Singh, "Implementation of Differential Services Based on Prority, Token Bucket, Round Robin Algorithms,” Int. J. Comput. Sci. Mob. Comput., vol. 4, pp. 810-818, 2015.

[10] D. H. Hailu, et al., "QoS Performance of Integrated Hybrid Optical Network in Mobile Fronthual networks," Indones. J. Electr. Eng. Comput. Sci., vol. 7, pp. 189-204, 2017.

[11] M. H. Hizburrahman, et al., "Analisis Unjuk Kerja Flow Control pada Network on Chip dalam Beberapa Kondisi Jaringan," J. Tek. ITS, vol. 4, pp. 217-222, 2015.

[12] A. D. M. Sharmya and F. Ida, "Reciver Based Flow Control With Backpressure Routing," Int. J. Adv. Eng. Res. Dev., vol. 2, pp. 306-314, 2015.

[13] I. P. A. E. Pratama, "Handbook Jaringan Komputer Teori dan Praktik Berbasiskan Open Source," 1st ed, Bandung, Informatika Bandung, 2014.

[14] T. Tsai, et al., "CAC and Packet Scheduling Using Token Bucket,” J. Commun., vol. 1, pp. 30-37, 2006.

[15] R. Wulandari, "Analisis QoS (Quality of Service) Pada Jaringan Internet (Studi Kasus: UPT Loka Uji Teknik Penambangan Jampang Kulon - LIPI)," J. Tek. Inform. dan Sist. Inf., vol. 2, pp. 162-172, 2016.

[16] R. Mahadevan and N. Anbazhagan, "An Efficient Framework to Improve QoS of CSP using Enhanced Minimal Resource Optimization based Scheduling Algorithm," Indones. J. Electr. Eng. Comput. Sci., vol. 12, pp. 11791186, 2018.

[17] C. P. Antodi, et al., "Penerapan Quality of Service Pada Jaringan Internet Menggunakan Metode Hierarchical Token Bucket," J. Teknol. dan Sist. Komput., vol. 5, pp. 23-28, 2017.

[18] A. Nurfajar, et al., "Desain dan Analisa Infrastruktur Jaringan Wired di PDII-LIPI Jakarta dengan Menggunakan Metode Network Development Life Cycle ( NDLC )," e-Proceeding Eng., vol. 2, pp. 5359-5365, 2015.

[19] D. Stiawan, "Fundamental Internetworking Development \& Design Life Cycle," pp. 1-13, 2009.

[20] F. A. Salman, "Implementation of IPsec-VPN Tunneling using GNS3," Indones. J. Electr. Eng. Comput. Sci., vol. 7, pp. 855-860, 2017.

[21] Yanto, "Analisis Qos (Quality of Service) Pada Jaringan Internet (Studi Kasus: Fakultas Teknik Universitas Tanjungpura)," pp. 1-6, 2013.

[22] P. E. Pratiwi, et al., "Analisis QoS Pada Jaringan Multi Protocol Label Switching (MPLS) Studi Kasus Di Pelabuhan Indonesia III Cabang Tanjung Intan Cilacap,” pp. 1-10, 2014.

[23] W. A. N. Wan Abdullah, et al., "Corrupted packets discarding mechanism to alleviate congestion in wireless body area network," vol. 14, pp. 581-587, 2019.

[24] Y. A. Pranata, et al., "Analisis Optimasi Kinerja Quality Of Service Pada Layanan Komunikasi Data Menggunakan NS - 2 di PT . PLN ( PERSERO ) Jember,” Sinergi, vol. 20, pp. 149-156, 2016.

[25] TIPHON, "Telecommunications and Internet Protocol Harmonization Over Networks (TIPHON) General aspects of Quality of Service," vol. 1, pp. 1-37, 1999. 